\section{Kidney \\ Blood Pressure Research}

\title{
TNF- $\alpha$ Deficiency Prevents Renal Inflammation and Oxidative Stress in Obese Mice
}

\author{
Huaiguo Wang ${ }^{a}$ Jian Lib ${ }^{b}$ Zhibo Gaic Gerd A. Kullak-Ublick ${ }^{c}$ Zewei Liu \\ aDepartment of Nephrology; 'Department of Endocrinology, Liaocheng People's Hospital, Liaocheng, \\ Shandong Province, China; 'Department of Clinical Pharmacology and Toxicology, University Hospital \\ Zurich, Zurich, Switzerland
}

\section{Key Words}

High-fat diet $\bullet$ Obesity $\bullet$ TNF- $\alpha \cdot$ Inflammation $\bullet$ Oxidative stress $\bullet$ Apoptosis $\bullet$ Glomerulosclerosis - Renal fibrosis

\begin{abstract}
Background/Aims: Obese patients and experimental animals exhibit high levels of inflammatory cytokines, such as tumor necrosis factor (TNF)- $\alpha$. However, the role of TNF- $\alpha$ in the pathophysiologic process in obesity induced kidney damage is still unknown. Methods: We used TNF- $\alpha$ deficient mice and wild-type (WT) C57/BJ6 mice controls to study the effect of TNF- $\alpha$ on inflammation and oxidative stress in kidney by the model of high-fat diet (HFD) and primary isolated mouse renal proximal tubule cells treated with a mixture of free fatty acids (FFA). Results: Compared with the chow diet group, HFD-fed WT mice had higher urinary albumin and increased levels of renal fibrosis, glomerulosclerosis, inflammation, oxidative stress and apoptosis in the kidney. These changes were co-related with increased expression of TNF- $\alpha$ in the kidney and were attenuated by TNF- $\alpha$ deficiency. In vitro, accumulation of intracellular lipids induced TNF- $\alpha$ expression and oxidative stress in FFA treated primary proximal tubule cells. However, TNF- $\alpha$ inhibition with siRNA or TNF- $\alpha$ deficiency decreased the lipid induced oxidative stress in these cells. Conclusion: These findings suggest that TNF- $\alpha$ plays an important role in the HFD induced kidney damage, and targeting TNF- $\alpha$ and/or its receptors could be a promising therapeutic regimen for progressive nephropathy.
\end{abstract}




\section{Kidney Blood Pressure Research}

Wang et al.: TNF- $\alpha$ Deficiency Prevents Renal Oxidative Stress

\section{Introduction}

Emerging evidence from clinical and experimental studies suggests that obesity is a chronic pro-inflammatory disease of multifactorial origin with many organs affected by fat accumulation and inflammation [1,2]. Recently, the studies demonstrated the prevalence of obesity induced kidney damage, which could cause glomerulusclerosis, proteinuria and renal fibrosis [3-5]. With the marked increase in the prevalence of obesity in adults and children $[6,7]$, it has become more important to identify and characterize novel mechanisms in obesity induced kidney disease.

An increasing number of investigations have recently implicated a rather unique role for inflammation and oxidative stress in the pathogenesis of kidney damage in obesity [810]. This is consistent with the notion that obesity is recognized as a chronic low-grade systemic inflammatory disease with accumulation of pro-inflammatory cytokines, such as tumor necrosis factor (TNF)- $\alpha$, during the onset and progression of obesity [9]. TNF- $\alpha$ was initially identified as a factor that causes transplanted tumors to undergo hemorrhagic necrosis [11], but later came to be known as a multifunctional cytokine with a role in various disease states, including inflammation and obesity [9, 12].

It has been shown that TNF- $\alpha$ levels are associated with the development of nephropathy [13], with diverse actions potentially involved in the development of complications [14]. In type 2 diabetic patients, serum and urine TNF- $\alpha$ level increased significantly with the degree of albuminuria [15]. In rats with renal failure, TNF- $\alpha$ naturalization prevented albuminuria, reduced fibrosis, decreased macrophage infiltration $[16,17]$. In TNF- $\alpha$ ob/ob mice, TNF- $\alpha$ inhibition alleviates tissue oxidative injury in several organs, including kidney [18]. Moreover, TNF- $\alpha$ plays an important role in inducing oxidative stress in cardiac myocyte hypertrophy and cardiac dysfunction [19-22]. However, the role of TNF- $\alpha$ in HFD induced oxidative stress during kidney damage is still unknown. Therefore, we tested the hypothesis that mice lacking TNF- $\alpha$ show protection from obesity-associated nephropathy and that TNF- $\alpha$ mediates obesity induced oxidative stress in kidney proximal tubule cells.

\section{Materials and Methods}

Experimental animals and tissue preparation

8-week-female TNF- $\alpha$ deficient (KO) mice and age matched C57/BJ6 wild-type (WT) mice were randomly assigned to feed with a high fat diet (D12331; ResearchDiets, NJ, USA) or control chow diet (ResearchDiets, NJ, USA) (n=8/group). All mice were sacrificed under anesthesia after 8 weeks food intervention and kidneys were harvested. Half of the kidney from each animal was snap frozen in liquid nitrogen and stored at $-80^{\circ} \mathrm{C}$ for RNA and protein extraction. The other half was fixed with formalin for histology. All protocols were approved by the Animal Care and Use Committee of Liaocheng People's Hospital (Shandong Province, China).

Measurement of plasma and urine samples

Laboratory parameters were measured as described [23]. For 24-hour urine collection, individual mice were placed in metabolic cages with access to diets. Urinary albumin and creatinine concentrations were measured with the Albumin mouse ELISA kit (ab108792, Abcam, Cambridge, UK) and Creatinine assay kit (ab65340, Abcam, Cambridge, UK). Urinary $\mathrm{H}_{2} \mathrm{O}_{2}$ levels were measured using the Amplex Red $\mathrm{H}_{2} \mathrm{O}_{2}$ assay kit (A12214, Invitrogen, CA, US). Urinary 8-isoprostane was measured using the 8-isoprostane EIA kit (516351, Cayman Chemical, Ann Arbor, US). Plasma samples were obtained from aorta blood of 4-hour fasted mice. Plasma cholesterol and triglyceride levels were measured by the Amplex Red cholesterol assay kit (A12216, Invitrogen, CA, US) and the Triglyceride assay kit (ETGA-200, EnzyChrom, Aachen, Germany), respectively.

Assessment of renal pathology and immunostaining

Kidneys were fixed overnight in 10\% neutral buffer formalin and embedded in paraffin. Tissue sections were cut at $4 \mu \mathrm{m}$ and stained for periodic acid-Schiff (PAS) and Masson's trichrome using standard protocols. Number of glomerulosclerosis was counted from PAS stained sections and fibrotic area was 


\section{Kidney Blood Pressure Research}

Kidney Blood Press Res 2017;42:416-427
\begin{tabular}{l|l}
\hline DOI: 10.1159/000478869 & (c) 2017 The Author(s). Published by S. Karger AG, Basel \\
Published onlIne: July 07, 2017 & www.karger.com/kbr
\end{tabular}

Wang et al.: TNF- $\alpha$ Deficiency Prevents Renal Oxidative Stress

assessed from trichrome stained sections as described [3, 24]. Briefly, a blind observer analyzed digital images of random high power fields [25]. The cross-sectional area of fibrosis was determined by using the program Adobe Photoshop [26]. Immunostaining was performed on paraffin sections using a microwave based antigen retrieval technique. The antibody against TNF $\alpha$ (Abcam, Cambridge, UK) was used for the detection of TNF-a. The antibody against 4-HNE (Abcam, Cambridge, UK) was used for the detection of 4-Hydroxynonenal. Sections were treated with the Envision ${ }^{+}$DAB kit (Dako, Denmark) according to the manufacturer's instruction.

Isolation of kidney RNA and quantification of transcript levels

Total RNA from frozen kidney was isolated by Trizol (Invitrogen, CA, US) and reverse transcribed using oligo-dT priming and SuperscriptII (Invitrogen, CA, US). First-strand complementary DNA was used as the template for real-time polymerase chain reaction analysis with TaqMan master mix and primers (Applied Biosystem, CA, US). Transcript levels were calculated as described and expressed relative to the villin housekeeping gene.

\section{TUNEL staining}

TUNEL staining was performed using a TACS TdT Kit (R\&D Systems). Briefly, following digestion with $20 \mu \mathrm{g} / \mathrm{ml}$ proteinase $\mathrm{K}$ for $15 \mathrm{~min}$ at room temperature, the sections from the kidneys were peroxidase blocked with $\mathrm{H}_{2} \mathrm{O}_{2}$ and sufficient amount of TUNEL reaction mixture was added to cover each section. The slides were then incubated in a humidified chamber for $60 \mathrm{~min}$ at $37^{\circ} \mathrm{C}$. After the reaction was stopped, the slides were counter-stained with $0.5 \%$ methyl green and examined by light microscopy. The number of TUNEL-positive cells was counted in each kidney section ( $\mathrm{n}=8$ kidneys per group, three sections per kidney) under high power magnification, and the mean number of TUNEL-positive cells was calculated as percent $/ 1000$ cells.

\section{Caspase 3 activity}

Caspase 3 activity was measured using caspase 3 assay kit (CASP3C, Sigma, St Louis, US) according to the manufacturer's instructions. Briefly, kidney tissue was homogenized and centrifuged at $10,000 \mathrm{~g}$ for 10 $\mathrm{min}$ at 4 degrees. The pellets were lysed and incubated with caspase 3 colorimetric substrate for 2 hours. Absorbance was read at $405 \mathrm{~nm}$ and caspase 3 activities were normalized to the protein concentration of kidney lysates.

\section{Kidney MPO detection}

Kidney myeloperoxidase was detected by a myeloperoxidase ELISA Kit (ThermoFisher Scientific). All procedures were performed according to manufacture's guideline.

\section{Cell culture, treatment, and oxidative stress staining}

Primary proximal tubule cells were isolated from kidneys of wild-type or TNF-a deficient mice as described previously [24,27]. Briefly, kidney cortices from mice were dissected, sliced, minced and digested in $0.25 \%$ trypsin solution (Life Technologies BRL, Grand Island, NY) in a shaking incubator at $37^{\circ} \mathrm{C}$ for 1 hour. Trypsin was neutralized with growth medium DMEM and the suspension was pipetted and was passed through a $100-\mu \mathrm{m}$ cell strainer. The samples were centrifuged ( $600 \mathrm{rpm}$ for 5 minutes) to pellet the tubules, washed with $10 \mathrm{ml}$ of medium, centrifuged, and washed twice more. The final pellet, consisting mostly of renal tubules, was re-suspended in culture medium (REBM bullet kit, Clonetics), plated onto culture dishes and incubated at $37^{\circ} \mathrm{C}$ in a carbon dioxide incubator with medium changes every 2 days until confluent. Experiments were carried out in serum-free DMEM. For Free fatty acids (FFA) studies, proximal tubule cells were incubated with a mixture oleate/palmitate (2:1) or vehicle for 24 hours as described elsewhere [28]. For the RNA interference experiment, cells were pretreated with TNF- $\alpha$ siRNA (50nM) for 24 hours before exposure to FFA. For oxidative stress detection, cells were incubated with CellROX reagent (C10422, Life Technologies) at 37 degree for 30 minutes and fixed with 3.7\% formaldehyde before imaging.

\section{Statistical analysis}

Data are expressed as mean \pm SEM. Data comparison between groups was assessed by one-way ANOVA followed by Bonferroni's test. Statistical analyses were performed with GraphPad software. 


\section{Kidney Blood Pressure Research}

Table 1. Effect of high-fat diet on body weight, kidney weight, plasma cholesterol and triglyceride and urinary albumin levels. Values are means \pm SEM; $n=8$ /group. CHO, cholesterol; TG, triglyceride; $\mathrm{Al}$, albumin; Cr, creatinine. ${ }^{*} p<0.05$, comparison between chow and HFD; ${ }^{\S} p<0.05$, comparison between HFD-WT and HFD-KO. Normal ranges are from JAX Genomic Medicine, the Jackson Laboratory.

\begin{tabular}{lcccc}
\hline Groups & Chow-WT (N = 8) & HFD-WT (N = 8) & HFD-KO (N=8) & Normal range\# $^{\#}$ \\
\hline Body weight (g) & $19.5 \pm 1.50$ & $25.5 \pm 1.23^{*}$ & $25.8 \pm 1.01^{*}$ & $22.6 \pm 1.8$ \\
Kidney weight (mg) & $131.3 \pm 3.98$ & $146.3 \pm 2.63^{*}$ & $143.8 \pm 3.24^{*}$ & $138.2 \pm 4.1$ \\
Plasma CHO (mg/dl) & $68.4 \pm 1.92$ & $85.6 \pm 2.34^{*}$ & $90.2 \pm 2.89^{*}$ & \\
Plasma TG (mg/dl) & $51.0 \pm 3.70$ & $62.2 \pm 3.88^{*}$ & $64.1 \pm 2.96^{*}$ & \\
Urinary Al/Cr (mg/g) & $124.0 \pm 7.9$ & $183.2 \pm 13.6^{*}$ & $151.4 \pm 5.7^{* \S}$ & \\
\hline
\end{tabular}

\section{Results}

General features of high-fat diet induced obese mice

To analyze the effect of TNF- $\alpha$ in high-fat diet (HFD) induced kidney damage, TNF- $\alpha$ deficient mice (KO) were treated by high-fat diet (HFD-KO) and were compared with wild-type mice (WT), which were treated by either normal chow (chow-WT) or high-fat diet (HFD-WT). TNF- $\alpha$ deficient mice develop normally and have no gross structural or morphological abnormalities compared with wild-type mice. As expected, after 8 weeks of dietary intervention, both HFD-WT and HFD-KO mice had higher bodyweight than agematched chow-WT controls (Table 1). Kidney weight was increased by HFD feeding (Table 1). Plasma levels of cholesterol and triglyceride were significantly higher in HFD induced obese WT and KO mice (Table 1). TNF- $\alpha$ deficiency did not affect bodyweight and kidney weight, as well as plasma cholesterol and triglyceride levels, indicating a similar change of obesity in both groups. On the other hand, urinary albumin/ creatinine ratio was significantly increased in obese HFD-WT mice, which suggests kidney damage incurred by HFD (Table 1). Urinary albumin/creatinine ratio is applied to test the risk of developing kidney disease. Interestingly, TNF- $\alpha$ deficiency markedly reduced albuminuria by $50 \%$ approximately, which indicates a negative role of TNF- $\alpha$ in HFD induced kidney dysfunction (Table 1).

TNF- $\alpha$ deficiency protects kidney from high-fat diet induced renal fibrosis and glomerulosclerosis

HFD induced obesity caused significant histological changes in the kidney, characterized by deposition of interstitial matrices and focal glomerulosclerosis [4, 28]. Masson and PAS staining showed representative histologic findings at 8 weeks after HFD in WT mice (Fig. $1 \mathrm{~A} \mathrm{~b}, \mathrm{e}$ and $\mathrm{B} \mathrm{b}, \mathrm{e}$ ). These changes were less severe in HFD-KO mice (Fig. 1A c, $\mathrm{f}$ and $\mathrm{B} \mathrm{c}$, f). To examine these pathological changes quantitatively, the interstitial fibrosis area and the glomerulosclerosis in every specimen were measured. Interstitial fibrosis deposition was increased approximately 5-fold in the kidneys of HFD-WT mice compared to kidneys of chow-WT mice (Fig. 1B). Besides, HFD increased the number of PAS positive staining glomeruli in WT kidney (Fig. 1C). However, these increases were less severe in HFD-KO mice than in WT obese mice, indicating that TNF- $\alpha$ deficiency protected kidney from HFD induced interstitial fibrosis and glomerulosclerosis.

TNF- $\alpha$ deficiency abates HFD induced inflammation, oxidative stress and apoptosis

To determine the mechanism of glomerular and tubulointerstitial damage, we examined markers of inflammation, macrophage infiltration and oxidative stress, three major pathways induced by TNF- $\alpha$. HFD resulted in significant over-expression of TNF- $\alpha$ at both protein and mRNA levels in the kidneys of HFD-WT mice (Fig. 2A b and B). As a negative control, TNF- $\alpha$ deficient mice did not show any expression of TNF- $\alpha$ after HFD intervention (Fig. 2A c and B). 


\section{Kidney Blood Pressure Research}

Fig. 1. Histological analysis of kidney tissues from 3 groups. A. Representative images of Masson trichrome stained renal sections of Chow-WT (a), HFD-WT (b) and HFD-KO mice(c). C. Representative images of PAS stained kidney of Chow-WT (a), HFD-WT (b) and HFD-KO mice(c). Scale bar: $50 \mu \mathrm{m}$. $\mathrm{B}$ and D. Bars represent the quantitative analysis of (C) area of fibrosis and (D) percentage of glomerulosclerosis where data are expressed as the mean $\pm \mathrm{SEM}$, * $p<0.05$, comparison between Chow and HFD; ${ }^{\S} p<$ 0.05 , comparison between HFD-WT and HFD-KO.

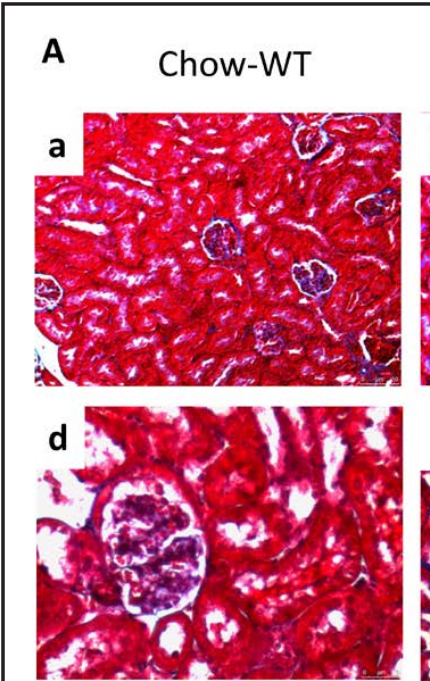

B

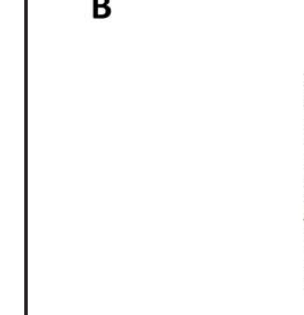

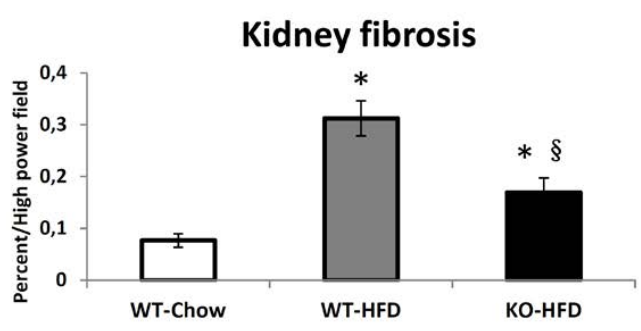
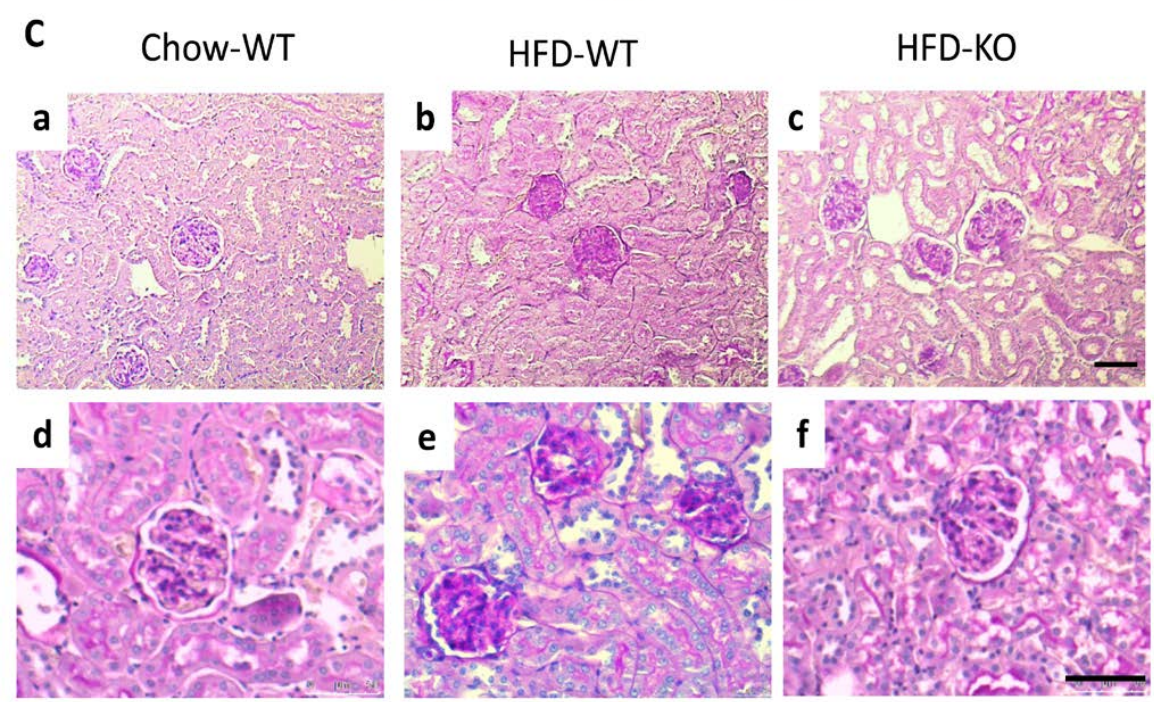

D

Kidney glomerulosclerosis

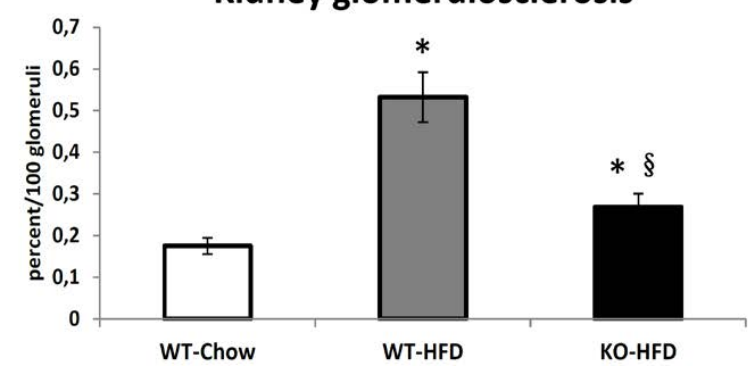




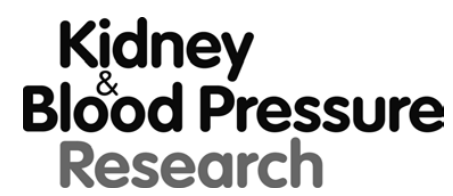

\begin{tabular}{l|l}
\hline Kidney Blood Press Res 2017;42:416-427 \\
\hline \begin{tabular}{l|l} 
DOI: 10.1159/000478869 & (c) 2017 The Author(s). Published by S. Karger AG, Basel \\
wublished onlıne: July 07, 2017 & ww.karger.com/kbr
\end{tabular}
\end{tabular}

Wang et al.: TNF- $\alpha$ Deficiency Prevents Renal Oxidative Stress

The mRNA expression levels of F4/80, IL1ßand IL6 were markedly increased in the HFDWT kidney and decreased in the HFD-KO kidney, indicating less macrophage and monocyte infiltration in TNF- $\alpha$ deficient mice (Fig.2C, D and E). Moreover, myeloperoxidase (MPO), a peroxidase enzyme relates directly to inflammation initiation and oxidative damage, was increased in the HFD-WT and decreased in the HFD-KO kidney (Fig. 2F).

Because TNF- $\alpha$ is proposed to be the major contributor to oxidative stress in obesity [9, $10,29]$, we tested urinary $\mathrm{H}_{2} \mathrm{O}_{2}$, 8-isoprostane and checked immunostaining for 4-HNE on kidney sections, all of which are markers for oxidative stress. In HFD-WT group, the urinary levels of $\mathrm{H}_{2} \mathrm{O}_{2}$ and 8-isoprostane and the intensity of 4-HNE staining were markedly elevated (Fig. 2G, $\mathrm{H}$ and I b), suggesting that enhanced oxidative stress was induced by HFD. TNF- $\alpha$ deficiency significantly reduced the elevated levels of urinary $\mathrm{H}_{2} \mathrm{O}_{2}$ and 8-isoprostane and the increased 4-HNE (Fig. 2G, H and I c). At the meanwhile, HFD induced significant increases of Nox2 and Nox4 mRNA expression and a decrease in the mRNA expression levels of $\mathrm{Cu}$, Zn-SOD, an antioxidant enzyme, which protects tissues from oxidative stress, in the HFD-WT kidneys. Instead, these changes were abated by TNF- $\alpha$ deficiency (Fig. 2J, K and L).

Given that elevated TNF- $\alpha$ and oxidative stress levels could cause DNA damage and apoptosis, we checked TUNEL staining of kidney sections from each group. Positive staining of apoptotic cells (indicated by arrows) was markedly increased in the HFD-WT kidneys compared with the chow-WT kidneys, however, the extent of positive staining was limited in the HFD-KO kidneys (Fig. 3A a to c). A quantitative analysis showed that the amount of apoptotic bodies in HFD-WT kidneys was approximately 2 times higher than in Chow-WT and HFD-KO kidneys (Fig. 3B). Caspase 3 belongs to a family of evolutionarily conserved cysteine proteases that play a permissive role for cell apoptosis. In the present study, caspase 3 activity results confirmed the result of TUNEL staining (Fig. 3C). HFD-WT kidneys showed a higher caspase 3 activity than chow-WT kidneys, and HFD induced apoptosis was declined by TNF- $\alpha$ deficiency.

Taken together, these data suggest that HFD-induced TNF- $\alpha$ overexpression could result in inflammation, macrophage infiltration and oxidative stress in the kidney, and that TNF- $\alpha$ deficiency abates such damage.

Regulation of oxidative stress in proximal tubule cells incubated with free fatty acids

Free fatty acid (FFA) accumulation is among the main causes of obesity induced oxidative stress [30]. To address if the elevated oxidative stress in HFD-WT kidney is mediated by TNF- $\alpha$, we isolated kidney proximal tubule cells from the WT and TNF- $\alpha$ deficient mice, and incubated the cells with a free fatty acid mixture. Subsequently the expression of TNF- $\alpha$ and inflammatory cytokines and the level of oxidative stress were measured. TNF- $\alpha$ was increased at the mRNA level in WT cells after FFA treatment, whereas this increase was abrogated in the WT cells, which were pretreated with TNF- $\alpha$ siRNA (Fig. 4A). As a negative control, cells from TNF- $\alpha$ deficient mice did not show any expression of TNF- $\alpha$ (Fig. 4A). These results indicate that free fatty acids directly induce TNF- $\alpha$ expression in the kidney. Meanwhile, mRNA expression levels IL6 were also induced by FFA in WT cells, indicating that TNF- $\alpha$ de novo synthesis in the proximal tubule cells could promote the expression of inflammatory cytokines (Fig. 4B). However, these increases were abolished by TNF- $\alpha$ deficiency. Moreover, detection of oxidative stress by deep red probes showed a higher degree of staining in WT cells with FFA treatment than control WT cells (Fig. 4C a and b). The intensity of the signal from positive staining was less in TNF- $\alpha$ siRNA pretreated cells or in KO cells, which is in agreement with the results of urinary and mRNA analysis obtained from obese mice (Fig. 4C $c$ and d). In conclusion, these results suggest that TNF- $\alpha$ could mediate FFA induced oxidative stress and a decrease in TNF- $\alpha$ expression could protect kidney proximal tubule cells.

\section{Discussion}

In summary, the present study demonstrates that TNF- $\alpha$ deficiency protects the kidney against inflammation, oxidative stress and apoptotic injury in obesity. In this study, HFD 


\section{Kidney Blood Pressure Research}

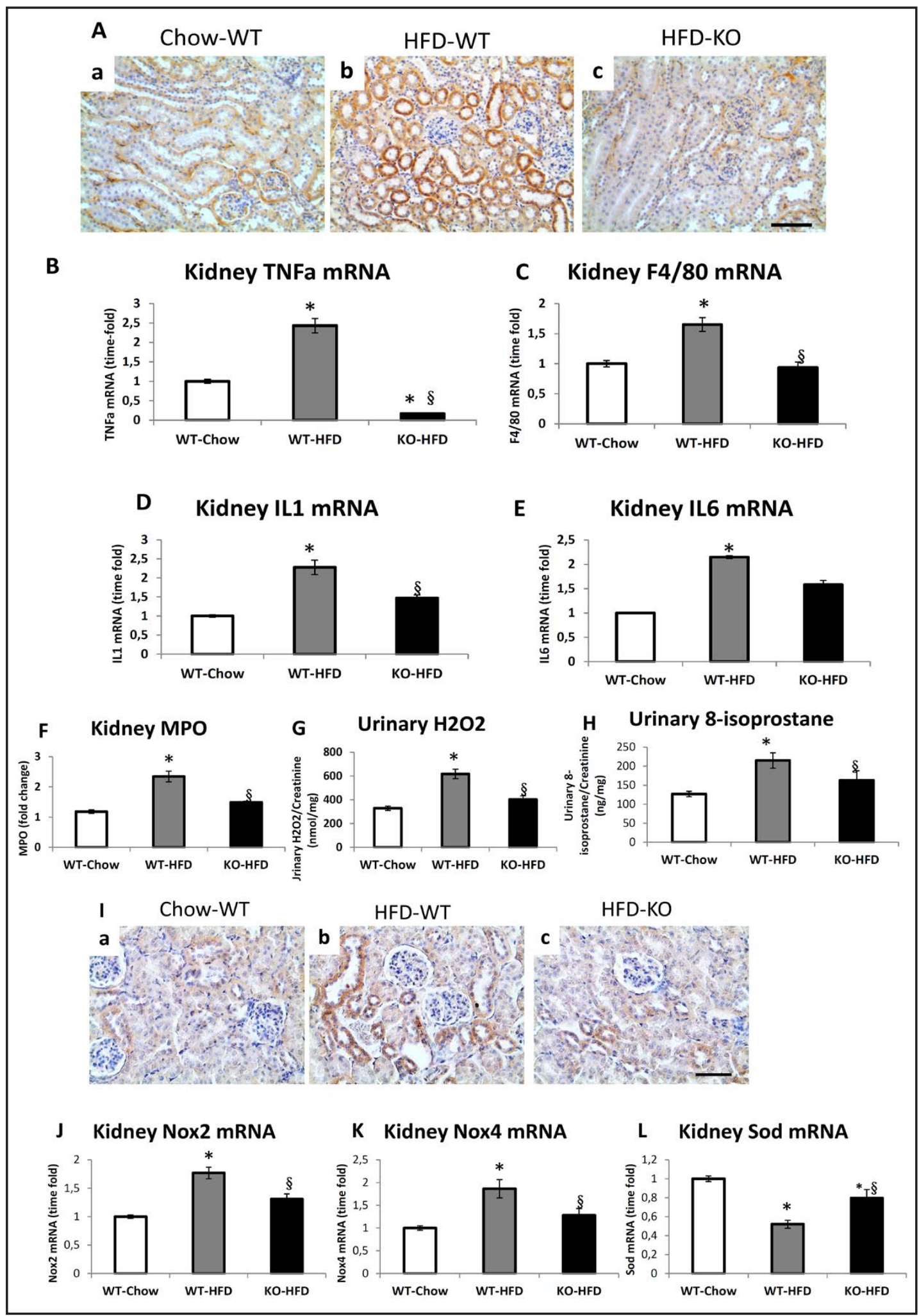

Fig. 2. Analysis of TNF- $\alpha$ induced inflammation, macrophage infiltration and oxidative stress from 3 groups. A. Representative immunohistochemistry images of TNF- $\alpha$ expression in kidney sections of Chow-WT (a), HFD-WT (b) and HFD-KO mice (c). Scale bar: $50 \mu \mathrm{m}$. B-E. Bars represent the quantitative TaqMan PCR analysis of TNF- $\alpha$, F4/80, IL1 and IL6 mRNA levels from the three treatment groups where data are expressed 


\section{Kidney Blood Pressure Research}

as the mean $\pm \mathrm{SEM},{ }^{*} p<0.05$, comparison between Chow and HFD; ${ }^{\S} p<0.05$, comparison between HFD-WT and HFD-KO. F-H. The relative levels of kidney myeloperoxidase (F), urinary $\mathrm{H}_{2} \mathrm{O}_{2}(\mathrm{G})$ and 8-isoprostane $(\mathrm{H})$ levels from the three treatment groups. The data are expressed as the mean $\pm \mathrm{SEM}, * p<0.05$, comparison between Chow and HFD; ${ }^{\S} p<0.05$, comparison between HFD-WT and HFD-KO. I. Representative immunohistochemistry images of 4-HNE in kidney sections of Chow-WT (a), HFD-WT (b) and HFD-KO mice (c). Scale bar: $50 \mu \mathrm{m}$. J-L. kidney Nox2 (J), Nox4 (K) and Sod (L) mRNA level from the three treatment groups. The data are expressed as the mean \pm SEM, $* p<0.05$, comparison between Chow and HFD; ${ }^{\S} p<0.05$, comparison between HFD-WT and HFD-KO.

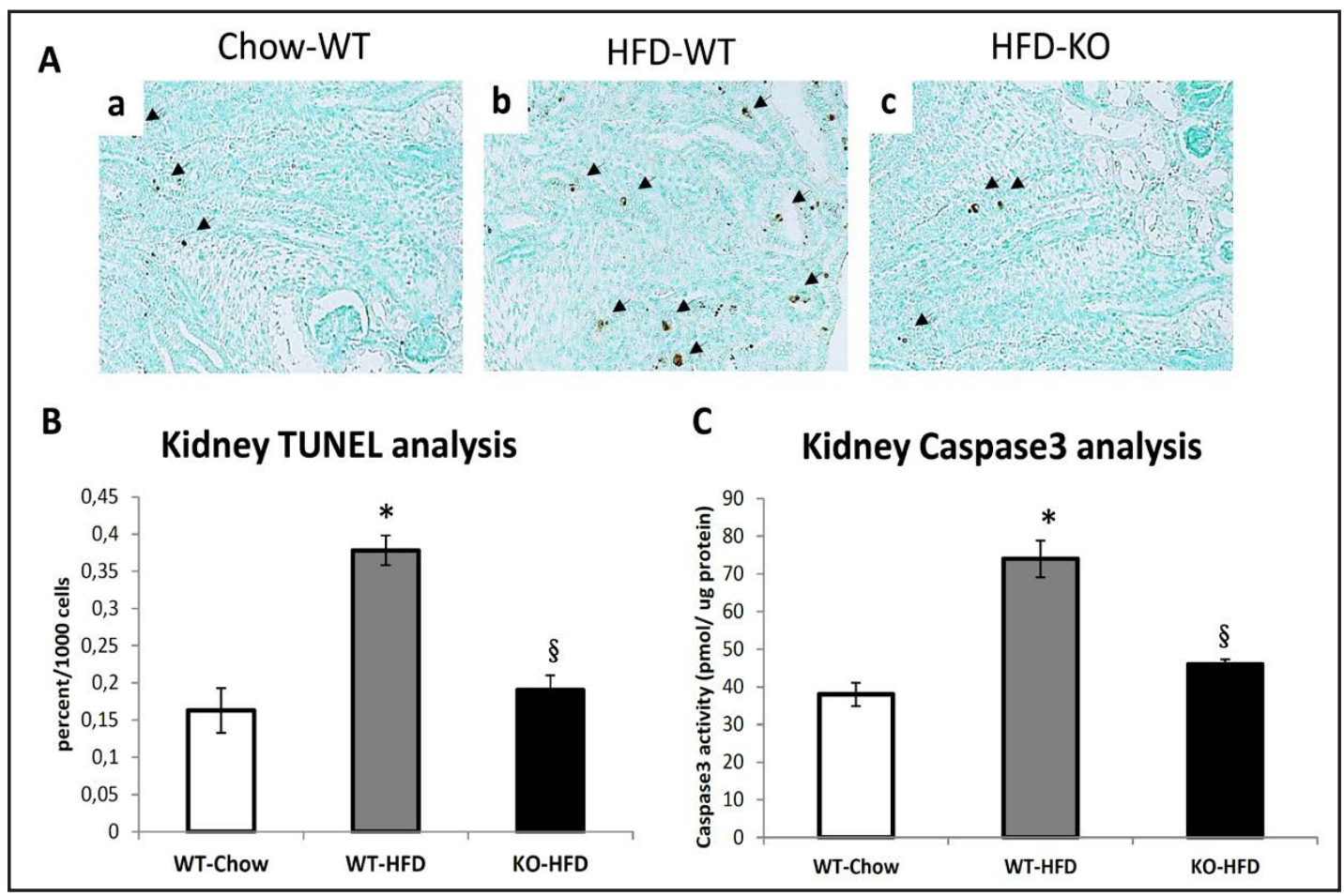

Fig. 3. Analysis of markers for apoptosis from the three groups. A. Representative images of TUNEL staining of kidney sections of Chow-WT (a), HFD-WT (b) and HFD-KO mice (c). The TUNEL-positive cells are indicated by arrows. B and C. Bars represent the quantitative analysis of TUNEL positive staining (B) and kidney caspase 3 (C) levels from the three treatment groups where data are expressed as the mean \pm SEM, * $p<$ 0.05, comparison between Chow and HFD; ${ }^{\S} p<0.05$, comparison between HFD-WT and HFD-KO.

led to higher plasma levels of cholesterol and triglyceride, however, TNF- $\alpha$ deficiency did not affect these parameters. Nonetheless, TNF- $\alpha$ deficiency significantly attenuated obesity induced albuminuria and kidney damage, favoring the beneficial effect of TNF- $\alpha$ deficiency and the decrease in inflammation, oxidative stress status and apoptosis. Further analysis revealed elevated levels of apoptosis-associated markers TNF- $\alpha$, caspase 3 and the number of apoptotic bodies in the kidneys from obese mice. Intriguingly, TNF- $\alpha$ deficiency attenuated, to various extents, obesity-associated increases in these markers in the kidney. Moreover, primary culture of renal proximal tubule cells revealed that free fatty acids (FFA) induced the expression of TNF- $\alpha$ which could further result in oxidative stress. Both TNF- $\alpha$ inhibition and TNF- $\alpha$ deficiency could decrease FFA induced oxidative stress in these epithelial cells. Collectively, these data indicate that TNF- $\alpha$ plays an important role in obesity induced kidney damage and TNF- $\alpha$ deficiency could result in potential benefits in kidney function, possibly via attenuation of inflammation, oxidative injury and apoptosis.

Obesity is associated with impaired lipid metabolism and insulin resistance [31], which are promoted by elevated inflammatory cytokine levels $[9,32]$. This is supported by our 


\section{Kidney Blood Pressure Research}

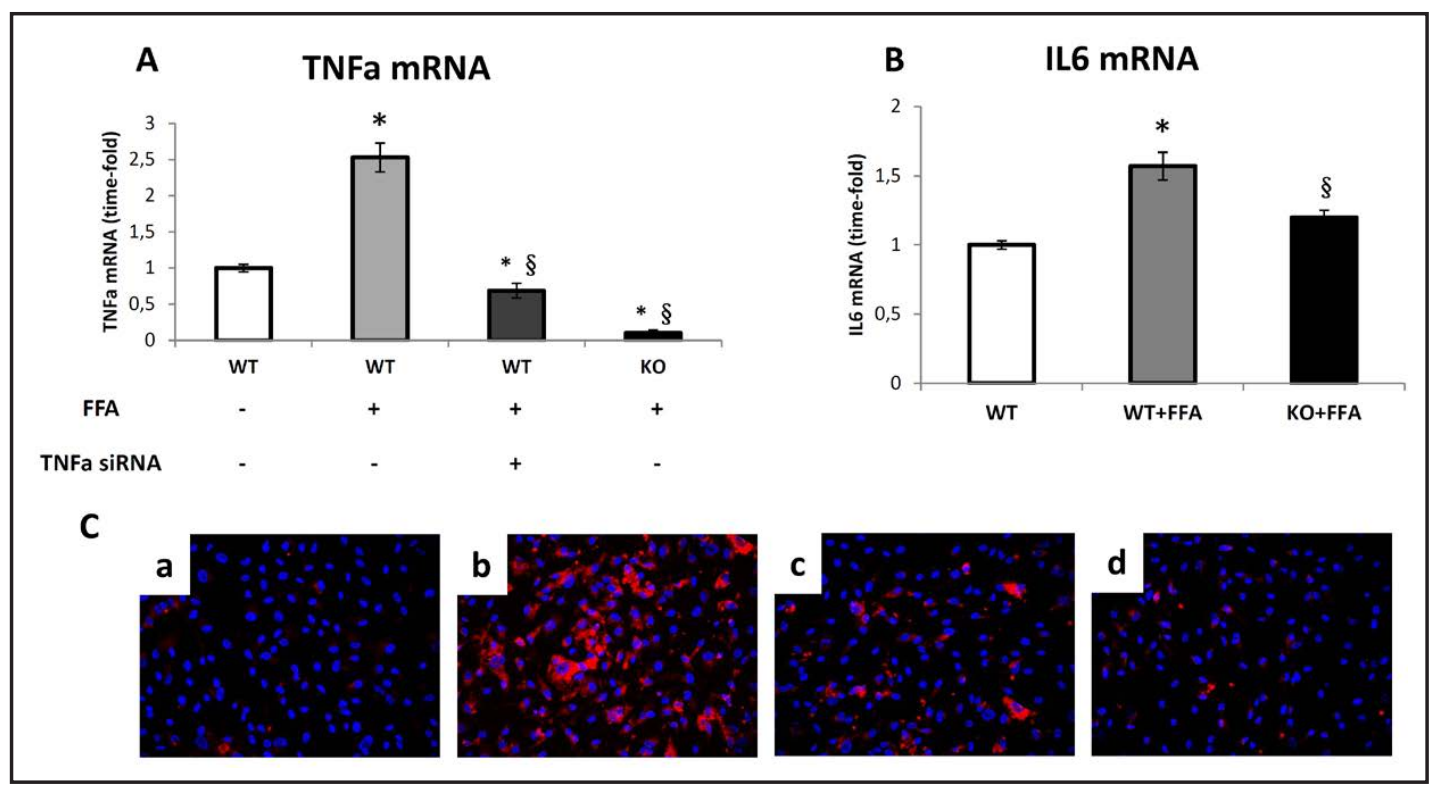

Fig. 4. Analysis of renal proximal tubule cells exposure to FFA. A. Bars represent the quantitative TaqMan PCR analysis of TNF- $\alpha$ mRNA levels from the three treatment WT cell groups as well as the TNF- $\alpha$ null cells. B. Bars represent the quantitative TaqMan PCR analysis of IL6 mRNA levels from the three treatment proximal tubule cell groups. Data are expressed as the mean $\pm \mathrm{SEM},{ }^{*} p<0.05$, comparison between WT-negative control; ${ }^{\S} p<0.05$, comparison between WT cells exposure to FFA. C. Representative images of CellROX staining of kidney proximal tubule cells which are (a) WT-negative control, (b) WT cells exposure to FFA, (c) TNF- $\alpha$ siRNA pretreated WT cells exposure to FFA and (d) TNF- $\alpha$ deficient (KO) cells exposure to FFA.

observation of hypercholesterolemia and hypertriglyceridemia in HFD induced obese mice. TNF- $\alpha$ could promote hepatic steatosis by inducing Srebp-1c and disrupting phospholipid homeostasis in mice with nonalcoholic steatohepatitis [33, 34]. Moreover, pro-inflammatory cytokines, such as TNF- $\alpha$ and IL6, regulate the expression of lipid transporters, namely MDRs and MRPs, which could affect the excretory capacity for lipids and anionic conjugates [35]. Although it was reported that fasting plasma glucose was significantly decreased in obese TNF deficient mice compared to obese wild type controls, characterization of TNF deficient homozygotes injected with gold-thioglucose to induce hyperphagic obesity indicates that the presence of TNF- $\alpha$ does not affect the degree of obesity [36]. Consistent with that, the present study showed that direct deficiency of TNF-a failed to alter obesityassociated hypercholesterolemia and hypertriglyceridemia, which indicates that additional factors are involved in such disorders. Our previous study of microarray analysis examined genes differentially expressed in the kidney from obese mice and found out that the Fxr (farnesoid x receptor) signaling pathway was activated [3]. Since Fxr is a bile acid receptor regulating glucose and lipid homeostasis, it is likely to play a key role in obesity induced kidney damage [37]. Further in vitro and in vivo studies are required to elucidate these potential mechanisms.

Obese individuals and experimental animals often exhibit higher levels of inflammation and oxidative stress $[9,10]$, which are related to increased adiposity and fat accumulation. Chronic inflammation and oxidative stress in obesity result in the onset and development of kidney damage [38]. Tumor necrosis factor (TNF)- $\alpha$ is a molecule with central roles in inflammation and inflammation induced organ injury in obesity $[8,32,39]$. TNF- $\alpha$ could promote inflammation, induce oxidative stress and regulate apoptosis [10, 29, 40]. Targeting TNF- $\alpha$ and/or its receptors has been demonstrated as a promising therapeutic regimen for insulin resistance and type 2 diabetes [41]. Recent studies demonstrated that TNF- $\alpha$ inhibition could alleviate cardiomyocyte contractile dysfunction in ob/ob obese mice [42] 


\section{Kidney Blood Pressure Research}

and protect against myocardial ischemia/reperfusion injury [26]. In the present study, levels of TNF- $\alpha$ were significantly increased in the kidney of obese mice, which exhibited albuminuria and higher degrees of inflammation, oxidative stress and cell apoptosis. Moreover, TNF- $\alpha$ deficiency abated such pathophysiologic changes, which is in line with a recent study demonstrating that TNF- $\alpha$ inhibition alleviates kidney oxidative injury and apoptosis in ob/ob mice [18].

Lipid accumulation, which is common in obesity, leads to cellular dysfunction and injury. This process has been described in multiple tissues including the heart, liver and kidney. Such cellular dysfunction and injury result from accumulation of free fatty acids (FFA) and their toxic metabolites. However, FFA induced nephropathy and the role of TNF- $\alpha$ involved in such kidney damage are not fully understood. The proximal tubules may be particularly vulnerable to FFA due to its role in reabsorption of FFA. In our study, exposure of cultured proximal tubule cells to FFA led to an increase in TNF- $\alpha$, which could be inhibited by TNF- $\alpha$ siRNA treatment. Our results indicate a causative role of fat accumulation in increasing TNF- $\alpha$ levels in proximal tubular cells. Increased in vitro expression of TNF- $\alpha$ by proximal tubular cells incubated with FFA correlated with increased levels of oxidative stress and is in line with our in vivo experiments in obese mice. Furthermore, exposure of proximal tubular cells to FFA increased oxidative stress, and this increase was reversed by TNF- $\alpha$ inhibition or deficiency. These results indicate that FFA promotes oxidative stress through the induction of TNF- $\alpha$.

\section{Conclusion}

Taken together, high fat diet induced TNF- $\alpha$ expression in the kidney and elevated TNF- $\alpha$ expression result in inflammation, oxidative stress and apoptosis. Moreover, TNF- $\alpha$ deficiency protects kidney from obesity induced albuminuria and kidney damage. In vitro studies showed that TNF- $\alpha$ expression was induced by free fatty acids and that TNF- $\alpha$ could mediate free fatty acid-induced oxidative stress.

\section{Disclosure Statement}

The authors have no conflicts of interest to disclose as described by Kidney and Blood Pressure Research.

\section{Acknowledgements}

This study was supported by grant no. 320030_144193 from the Swiss National Science Foundation, the Swiss National Center for Competence in Research NCCR-Kidney.ch (to GAKU), and the International Fellowship Program (grant no. 246539) on Integrative Kidney Physiology and Pathophysiology (IKPP).

\section{References}

1 Must A, Spadano J, Coakley EH, Field AE, Colditz G, Dietz WH: The disease burden associated with overweight and obesity. JAMA 1999;282:1523-1529.

2 Xiong XQ, Chen WW, Zhu GQ: Adipose afferent reflex: sympathetic activation and obesity hypertension. Acta Physiol (Oxf) 2014;210:468-478.

-3 Gai Z, Hiller C, Chin SH, Hofstetter L, Stieger B, Konrad D, Kullak-Ublick GA: Uninephrectomy augments the effects of high fat diet induced obesity on gene expression in mouse kidney. Biochim Biophys Acta 2014;1842:1870-1878. 


\section{Kidney \\ Blood Pressure Research}

4 Kambham N, Markowitz GS, Valeri AM, Lin J, D'Agati VD: Obesity-related glomerulopathy: an emerging epidemic. Kidney Int 2001;59:1498-1509.

5 de Vries AP, Ruggenenti P, Ruan XZ, Praga M, Cruzado JM, Bajema IM, D'Agati VD, Lamb HJ, Pongrac Barlovic D, Hojs R, Abbate M, Rodriquez R, Mogensen CE, Porrini E, Diabesity E-EWG: Fatty kidney: emerging role of ectopic lipid in obesity-related renal disease. Lancet Diabetes Endocrinol 2014;2:417-426. Cheng HY: Midlife body mass index and total mortality. JAMA 2006;295:1772; author reply 1772.

Frerichs LM, Araz OM, Huang TT: Modeling social transmission dynamics of unhealthy behaviors for evaluating prevention and treatment interventions on childhood obesity. PLoS One 2013;8:e82887.

-8 Fernandez-Sanchez A, Madrigal-Santillan E, Bautista M, Esquivel-Soto J, Morales-Gonzalez A, EsquivelChirino C, Durante-Montiel I, Sanchez-Rivera G, Valadez-Vega C, Morales-Gonzalez JA: Inflammation, oxidative stress, and obesity. Int J Mol Sci 2011;12:3117-3132.

-9 Tzanavari T, Giannogonas P, Karalis KP: TNF-alpha and obesity. Curr Dir Autoimmun 2010;11:145-156.

10 Savini I, Catani MV, Evangelista D, Gasperi V, Avigliano L: Obesity-associated oxidative stress: strategies finalized to improve redox state. Int J Mol Sci 2013;14:10497-10538.

-11 Carswell EA, Old LJ, Kassel RL, Green S, Fiore N, Williamson B: An endotoxin-induced serum factor that causes necrosis of tumors. Proc Natl Acad Sci USA 1975;72:3666-3670.

12 Agrawal NK, Kant S: Targeting inflammation in diabetes: Newer therapeutic options. World J Diabetes 2014;5:697-710.

13 Tong F, Luo L, Liu D: Effect of Intervention in Mast Cell Function Before Reperfusion on Renal IschemiaReperfusion Injury in Rats. Kidney Blood Press Res 2016;41:335-344.

14 Ramesh G, Reeves WB: Inflammatory cytokines in acute renal failure. Kidney Int Suppl 2004;10.1111/ j.1523-1755.2004.09109.xS56-61.

-15 He FF, Li HQ, Huang QX, Wang QY, Jiang HJ, Chen S, Su H, Zhang C, Wang YM: Tumor Necrosis Factor-Alpha and 8-Hydroxy-2'-Deoxyguanosine are Associated with Elevated Urinary Angiopoietin-2 Level in Type 2 Diabetic Patients with Albuminuria. Kidney Blood Press Res 2015;40:355-365.

16 Tran LT, MacLeod KM, McNeill JH: Chronic etanercept treatment prevents the development of hypertension in fructose-fed rats. Mol Cell Biochem 2009;330:219-228.

17 Therrien FJ, Agharazii M, Lebel M, Lariviere R: Neutralization of tumor necrosis factor-alpha reduces renal fibrosis and hypertension in rats with renal failure. Am J Nephrol 2012;36:151-161.

18 Zhu X, Jiang S, Hu N, Luo F, Dong H, Kang YM, Jones KR, Zou Y, Xiong L, Ren J: Tumour necrosis factor-alpha inhibition with lenalidomide alleviates tissue oxidative injury and apoptosis in ob/ob obese mice. Clin Exp Pharmacol Physiol 2014;41:489-501.

19 Tsutamoto T, Wada A, Matsumoto T, Maeda K, Mabuchi N, Hayashi M, Tsutsui T, Ohnishi M, Sawaki M, Fujii M, Matsumoto T, Yamamoto T, Horie H, Sugimoto Y, Kinoshita M: Relationship between tumor necrosis factor-alpha production and oxidative stress in the failing hearts of patients with dilated cardiomyopathy. J Am Coll Cardiol 2001;37:2086-2092.

20 Nakamura K, Fushimi K, Kouchi H, Mihara K, Miyazaki M, Ohe T, Namba M: Inhibitory effects of antioxidants on neonatal rat cardiac myocyte hypertrophy induced by tumor necrosis factor-alpha and angiotensin II. Circulation 1998;98:794-799.

21 Suematsu N, Tsutsui H, Wen J, Kang D, Ikeuchi M, Ide T, Hayashidani S, Shiomi T, Kubota T, Hamasaki N, Takeshita A: Oxidative stress mediates tumor necrosis factor-alpha-induced mitochondrial DNA damage and dysfunction in cardiac myocytes. Circulation 2003;107:1418-1423.

22 Mariappan N, Soorappan RN, Haque M, Sriramula S, Francis J: TNF-alpha-induced mitochondrial oxidative stress and cardiac dysfunction: restoration by superoxide dismutase mimetic Tempol. Am J Physiol Heart Circ Physiol 2007;293:H2726-2737.

-23 Caliskan Y, Ozluk Y, Celik D, Oztop N, Aksoy A, Ucar AS, Yazici H, Kilicaslan I, Sever MS: The Clinical Significance of Uric Acid and Complement Activation in the Progression of IgA Nephropathy. Kidney Blood Press Res 2016;41:148-157.

24 Gai Z, Zhou G, Gui T, Itoh S, Oikawa K, Uetani K, Muragaki Y: Trps1 haploinsufficiency promotes renal fibrosis by increasing Arkadia expression. J Am Soc Nephrol 2010;21:1468-1476.

25 Tan M, Li W, Zou G, Zhang C, Fang J: Clinicopathological features and outcomes of IgA nephropathy with hematuria and/or minimal proteinuria. Kidney Blood Press Res 2015;40:200-206.

-26 Pei H, Song X, Peng C, Tan Y, Li Y, Li X, Ma S, Wang Q Huang R, Yang D, Li D, Gao E, Yang Y: TNF-alpha inhibitor protects against myocardial ischemia/reperfusion injury via Notch1-mediated suppression of oxidative/nitrative stress. Free Radic Biol Med 2015;82:114-121. 


\section{Kidney \\ Blood Pressure Research}

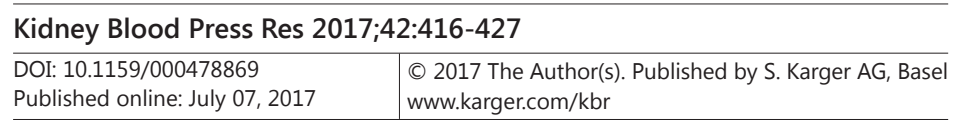

Wang et al.: TNF- $\alpha$ Deficiency Prevents Renal Oxidative Stress

27 Gai Z, Chu L, Hiller C, Arsenijevic D, Penno CA, Montani JP, Odermatt A, Kullak-Ublick GA: Effect of chronic renal failure on the hepatic, intestinal, and renal expression of bile acid transporters. Am J Physiol Renal Physiol 2014;306:F130-137.

28 Bobulescu IA, Dubree M, Zhang J, McLeroy P, Moe OW: Effect of renal lipid accumulation on proximal tubule $\mathrm{Na}+$ H+ exchange and ammonium secretion. Am J Physiol Renal Physiol 2008;294:F1315-1322.

-29 Nanami M, Ookawara T, Otaki Y, Ito K, Moriguchi R, Miyagawa K, Hasuike Y, Izumi M, Eguchi H, Suzuki $\mathrm{K}$, Nakanishi T: Tumor necrosis factor-alpha-induced iron sequestration and oxidative stress in human endothelial cells. Arterioscler Thromb Vasc Biol 2005;25:2495-2501.

30 Wahba IM, Mak RH: Obesity and obesity-initiated metabolic syndrome: mechanistic links to chronic kidney disease. Clin J Am Soc Nephrol 2007;2:550-562.

31 Kahn SE, Hull RL, Utzschneider KM: Mechanisms linking obesity to insulin resistance and type 2 diabetes. Nature 2006;444:840-846.

-32 Rodriguez-Hernandez H, Simental-Mendia LE, Rodriguez-Ramirez G, Reyes-Romero MA: Obesity and inflammation: epidemiology, risk factors, and markers of inflammation. Int J Endocrinol 2013;2013:678159.

-33 Endo M, Masaki T, Seike M, Yoshimatsu H: TNF-alpha induces hepatic steatosis in mice by enhancing gene expression of sterol regulatory element binding protein-1c (SREBP-1c). Exp Biol Med (Maywood) 2007;232:614-621.

34 Tanaka N, Matsubara T, Krausz KW, Patterson AD, Gonzalez FJ: Disruption of phospholipid and bile acid homeostasis in mice with nonalcoholic steatohepatitis. Hepatology 2012;56:118-129.

-35 Le Vee M, Lecureur V, Stieger B, Fardel O: Regulation of drug transporter expression in human hepatocytes exposed to the proinflammatory cytokines tumor necrosis factor-alpha or interleukin-6. Drug Metab Dispos 2009;37:685-693.

-36 Ventre J, Doebber T, Wu M, MacNaul K, Stevens K, Pasparakis M, Kollias G, Moller DE: Targeted disruption of the tumor necrosis factor-alpha gene: metabolic consequences in obese and nonobese mice. Diabetes 1997;46:1526-1531.

37 Gai Z, Gui T, Hiller C, Kullak-Ublick GA: Farnesoid X Receptor Protects against Kidney Injury in Uninephrectomized Obese Mice. J Biol Chem 2016;291:2397-2411.

-38 Sharma K: Obesity, oxidative stress, and fibrosis in chronic kidney disease. Kidney Int Suppl (2011) 2014;4:113-117.

39 Wang B, Trayhurn P: Acute and prolonged effects of TNF-alpha on the expression and secretion of inflammation-related adipokines by human adipocytes differentiated in culture. Pflugers Arch 2006;452:418-427.

40 Dandona P, Aljada A, Bandyopadhyay A: Inflammation: the link between insulin resistance, obesity and diabetes. Trends Immunol 2004;25:4-7.

41 Chatzigeorgiou A, Seijkens T, Zarzycka B, Engel D, Poggi M, van den Berg S, van den Berg S, Soehnlein O, Winkels H, Beckers L, Lievens D, Driessen A, Kusters P, Biessen E, Garcia-Martin R, Klotzsche-von Ameln A, Gijbels M, Noelle R, Boon L, Hackeng T, Schulte KM, Xu A, Vriend G, Nabuurs S, Chung KJ, Willems van Dijk K, Rensen PC, Gerdes N, de Winther M, Block NL, Schally AV, Weber C, Bornstein SR, Nicolaes G, Chavakis T, Lutgens E: Blocking CD40-TRAF6 signaling is a therapeutic target in obesity-associated insulin resistance. Proc Natl Acad Sci USA 2014;111:2686-2691.

42 Li L, Hua Y, Dong M, Li Q Smith DT, Yuan M, Jones KR, Ren J: Short-term lenalidomide (Revlimid) administration ameliorates cardiomyocyte contractile dysfunction in ob/ob obese mice. Obesity (Silver Spring) 2012;20:2174-2185. 